\title{
Methylphenidate and Central Precocious Puberty: A Probable Side Effect among Seven Children with the Attention Deficit Hyperactivity Disorder
}

\author{
Ayça Törel Ergür ${ }^{1}$, Hesna Gül ${ }^{2}$, Ahmet Gül ${ }^{3}$ \\ Departments of ${ }^{1}$ Pediatric Endocrinology and ${ }^{3}$ Psychiatry, Ufuk University School of Medicine, ${ }^{2}$ Department of Child and Adolescent Psychiatry, \\ Gulhane Training and Research Hospital, Ankara, Turkey
}

\begin{abstract}
Methylphenidate (MPH) is the most preferred drug for treatment of the attention deficit hyperactivity disorder (ADHD). Here, we aimed to discuss the possible effects and mechanisms of MPH on precocious puberty (PP) via a case series with seven children who had normal body mass index. In this case series we evaluated seven children with ADHD, who had received $\mathrm{MPH}$ for at least 6 months $(0.5 \mathrm{mg} / \mathrm{kg} /$ dose three times a day, maximum $60 \mathrm{mg})$ and admitted to Department of Pediatric Endocrinology with PP symptoms. The mean age was 8.16 years. Basal hormonal levels (luteinizing hormone [LH], follicle stimulating hormone, and estrogen/testosterone) were within normal range. Results of LH-releasing hormone stimulation tests demonstrated central pubertal responses. Glutamine, dopamine and noradrenaline are most important excitatory neurotransmitters that have a role at the beginning of puberty. The effect of $\mathrm{MPH}$, cumulating dopamine and noradrenaline in the synaptic gap could be associated with the acceleration of puberty with the excitatory effect of dopamine's gonadotropin-releasing hormone $(\mathrm{GnRH})$ release, excitatory effect of noradrenaline's GnRH release and the disappearance of $\mathrm{GnRH}$ receptor expression suppressor effect on prolactin disinhibitory effect.
\end{abstract}

KEY WORDS: Attention deficit hyperactivity disorder; Methylphenidate; Precocious puberty.

\section{INTRODUCTION}

The attention deficit hyperactivity disorder (ADHD) is the most common neurodevelopmental disorder (worldwide prevalence, $5.29 \%)^{1)}$ and is defined by persistent symptoms of inattention, hyperactivity and impulsivity. It is commonly diagnosed in childhood but could persist into adulthood with a margin that exceeds $60 \%{ }^{2)}$ For this psychiatric disease, methylphenidate (MPH) is the main psychostimulant drug prescribed to children and adolescents. ${ }^{3)}$ It acts by blocking the dopamine and noradrenaline transporters. ${ }^{4)}$

Some studies demonstrated that dopamine has an im-

Received: January 15, 2018 / Revised: February 17, 2018

Accepted: March 7, 2018

Address for correspondence: Hesna Gül

Department of Child and Adolescent Psychiatry, Gulhane

Training and Research Hospital, Emrah Mahallesi, Gen. Dr. Tevfik

Sağlam Cd 06010, Keçiören/Ankara, Turkey

E-mail: drhesnagul@gmail.com

ORCID: http://orcid.org/0000-0002-1696-1485 portant role in the prepubertal maturation stages and early exposure to $\mathrm{MPH}$ could lead to long-lasting alterations in brain dopamine pathways and natural reward systems ${ }^{5,6)}$ which are related to sexual behavior performance, alterations on hormonal profile and also with the negative effect on appetite and body mass index (BMI), delayed puberty. ${ }^{7,8)}$

In this brief report, we will discuss the possible effects and underpinning mechanisms of MPH on an unexpected side effect (precocious pubertal development, PPD) of seven children who had a normal BMI.

\section{CASE}

Children were treated with MPH $(0.5 \mathrm{mg} / \mathrm{kg} /$ dose three times a day, maximum $60 \mathrm{mg}$ ) at least for 6 months (6-12 months). Anthropometric evaluation, and endocrinological investigation were performed to all children at Department of Pediatric Endocrinology, Ufuk University

(c) This is an Open-Access article distributed under the terms of the Creative Commons Attribution Non-Commercial License (http://creativecommons.org/licenses/by-nc/4.0) which permits unrestricted non-commercial use, distribution, and reproduction in any medium, provided the original work is properly cited. 
in Ankara, Turkey. In this investigation, the pubertal development stages were assessed according to Marshall and Tanner scale and the bone age was assessed using the Greulich and Pyle atlas. PPD was diagnosed if the breast development started before the age of 8 years or menarche started before the age of 10 years in girls or and testis volumes were $>3 \mathrm{ml}$ before the age of 9 years in boys. Pelvic ultrasound, neuroradiological imaging and evaluation of the hypothalamic-pituitary-gonadal axis (HPGA) by measuring basal and stimulated luteinizing hormone (LH) and follicle stimulating hormone (FSH) peaks, and the plasma concentration of estradiol or testosterone were performed. Gonadotropin hormones were measured using the immunochemiluminometric method. Children were followed for at least 6 months after the diagnosis of PPD. MPH treatment was not ceased during follow-up. Anthropometric and pubertal evaluation, serum $\mathrm{LH}, \mathrm{FSH}$, estradiol or testosterone levels and pelvic ultrasonography was performed trimonthly. Written informed consent was obtained from the patients and their parents.

The mean age of the seven children ( 4 girls, 3 boys) was 8.16 years. Basal hormonal levels ( $\mathrm{LH}$, thyrotrophin stimulating hormone, estrogen /testosterone) were within normal range. $\mathrm{LH}$-releasing hormone $(\mathrm{LHRH})$ stimulation test was performed to all of the cases and results of the tests demonstrated central pubertal responses. Children all had normal range of brain magnetic resonance imaging (MRI). Table 1 shows the hormonal profiles, somatic progress, and prognosis of the children in detailed form. One child (Case 1) was put on gonadotropin-releasing hormone $(\mathrm{GnRH})$ analog treatment since she developed rapidly progressing PPD. Pubertal stage of the other cases didn't progress during 6 months interval.

\section{DISCUSSION}

Studies showed that ADHD is a complex neuropsychiatric disorder in which dopamine and noradrenaline systems of the brain affected. ${ }^{9)}$ The prefrontal cortex, orbitofrontal cortex, and basal ganglions are the dopamine-rich regions of the brain and functional MRI studies show that the cases with ADHD have decreased activity in prefrontal cortex and basal ganglions. ${ }^{10)} \mathrm{MPH}$ increases dopamine and noradrenaline level in the synaptic gap by the inhibition of the dopamine and noradrenaline transporters in these regions and reduce the symptoms.
PPD is a consequence of decreased activity of central suppressor system on $\mathrm{GnRH}$ neurons and the increased activity of the prominence excitatory systems. Glutamine, dopamine, and noradrenaline are the most important excitatory neurotransmitters that have a role in starting puberty. ${ }^{11)}$ The effect of $\mathrm{MPH}$, cumulating dopamine and noradrenaline in the synaptic gap, may induce puberty by affecting their own receptors. There are some animal study evidences that confirm this hypothesis; in the study of Adriani et al., ${ }^{12)} 2 \mathrm{mg} / \mathrm{kg} /$ day $\mathrm{MPH}$ and saline have been injected on 30 to 44 days old rats. They observed that in the MPH injected group, weight of testicles and amount of sperm have increased and these findings interpreted as subchronic MPH exposure in adolescent rats could have a trophic action on testis growth and a negative impact on testosterone metabolism. Davison and Kuenzel $^{13)}$ damaged the part of the lateral hypothalamus of 2 weeks old special chicken and observed increment of chicken testicles in size. They detected increased amount of hypothalamic biologic amines and dopamine in eminentia media. They related the enlargement of testicles with increased amount of dopamine, which has an excitatory effect on gonadotrophin release. ChatterjeeChakrabarty et al. ${ }^{14)}$ examined the effects of long-term $\mathrm{MPH}$ in the reproductive axis of adolescent female rats by comparing the results with drug-naive ones. They determined high level of $\mathrm{LH}$ in hypophysis and histologically premature luteinize ovarian follicles in the $\mathrm{MPH}$ group. The data about unexpected effects of MPH on reproductive system of children are extremely rare. Kelly et al. ${ }^{15)}$ reported a 12 years old prepubertal boy with recurrent erections who had been on MPH treatment for 2 years. In another case report, 7 years old girl with ADHD developed excessive hypersexual masturbation and behavior during $\mathrm{MPH}$ treatment. ${ }^{16)}$ Coskun and Zoroglu ${ }^{17)}$ reported 8 years old and 15 years old two boys who developed hypersexual behaviors and recurrent erections during MPH treatment. In one case report hypersexual behaviors and PPD are identified in children and adolescents due to clonidine treatment for ADHD, which is a noradrenaline receptor agonist. ${ }^{18)}$ On the other hand dopamine agonists show anti-prolactinergic effect with hypophyseal D2 receptor stimulation and studies showed that prolactin suppresses $\mathrm{GnRH}$ receptor expression in both hypophysis and hypothalamus. ${ }^{9)}$

As conclusion, using psychostimulant drugs at child- 


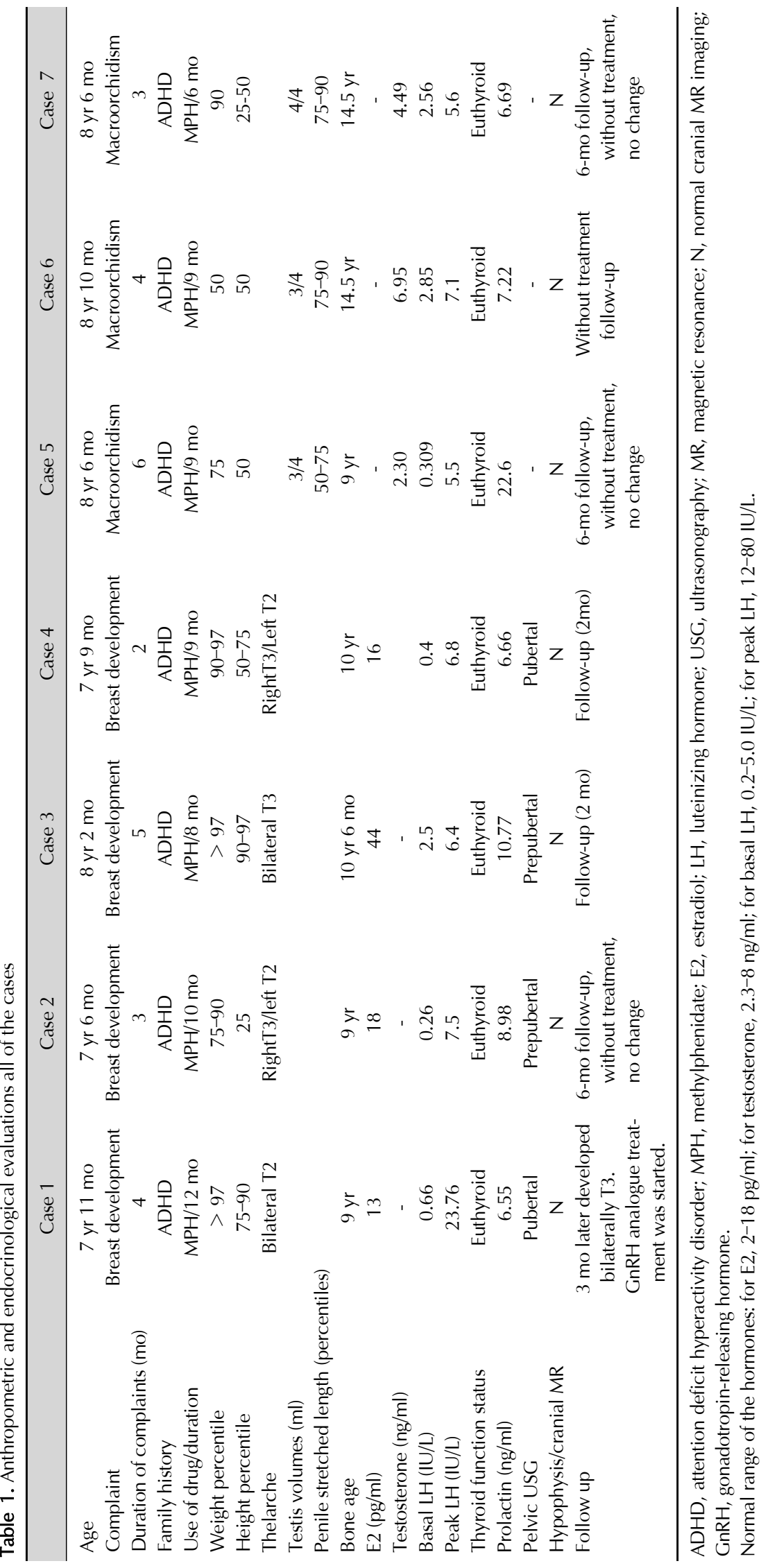


hood may accelerate puberty with the excitatory effect of dopamine's and noradrenaline's GnRH release and with the disappearance of $\mathrm{GnRH}$ receptor expression suppressor effect on prolactin's HPGA region with prolactin disinhibitory effect. In this case series, the story of PPD in $\mathrm{MPH}$ treated children with high/normal BMI is quite remarkable. Eventually, the facts discussed in the literature bring to mind a question: Could LHRH agonist treatment be effective when MPH and other drugs with similar mechanisms causing PPD? Even though the animal studies support our hypothesis, this possible side effect and LHRH treatment must be investigated in big samples of children and adolescents. According to these results, children who get MPH and have normal or high BMI should be evaluated more carefully for PPD during treatment.

\section{Acknowledgments}

This study was presented as a poster in ENDO 2016, 98th Annual Meeting and Expo of the Endocrine Society, 1-4 April 2016, Boston, MA, USA.

\section{Conflicts of Interest}

No potential conflict of interest relevant to this article was reported.

\section{REFERENCES}

1. Polanczyk G, de Lima MS, Horta BL, Biederman J, Rohde LA. The worldwide prevalence of ADHD: a systematic review and metaregression analysis. Am J Psychiatry 2007; 164:942-948.

2. Barkley RA, Fischer M, Smallish L, Fletcher K. The persistence of attention-deficit/hyperactivity disorder into young adulthood as a function of reporting source and definition of disorder. J Abnorm Psychol 2002; 111:279-289.

3. Gumy C, Huissoud T, Dubois-Arber F. Prevalence of methylphenidate prescription among school-aged children in a Swiss population: increase in the number of prescriptions in the Swiss Canton of Vaud, from 2002 to 2005, and changes in patient demographics. J Atten Disord 2010;14:267-272.

4. Kuczenski R, Segal DS. Effects of methylphenidate on extracellular dopamine, serotonin, and norepinephrine: comparison with amphetamine. I Neurochem 1997;68:20322037.

5. Montagnini BG, Silva LS, dos Santos AH, Anselmo-Franci JA, Fernandes GS, Mesquita Sde F, et al. Effects of repeated administration of methy/phenidate on reproductive parameters in male rats. Physiol Behav 2014;133:122-129.

6. Vidal B, Pasqualini C, Le Belle N, Holland MC, Sbaihi M, Vernier $\mathrm{P}$, et al. Dopamine inhibits luteinizing hormone synthesis and release in the juvenile European eel: a neuroendocrine lock for the onset of puberty. Biol Reprod 2004; 71 . 1491-1500.

7. Guarraci FA, Holifield C, Morales-Valenzuela J, Greene K, Brown J, Lopez R, et al. Exposure to methy/phenidate during peri-adolescence affects endocrine functioning and sexual behavior in female Long-Evans rats. Pharmacol Biochem Behav 2016;142:36-41.

8. Poulton AS, Melzer E, Tait PR, Garnett SP, Cowell CT, Baur $\mathrm{LA}$, et al. Growth and pubertal development of adolescent boys on stimulant medication for attention deficit hyperactivity disorder. Med J Aust 2013;198:29-32.

9. Beaulieu JM, Gainetdinov RR. The physiology, signaling, and pharmacology of dopamine receptors. Pharmacol Rev 2011; 63:182-217.

10. Dickstein SG, Bannon K, Castellanos FX, Milham MP. The neural correlates of attention deficit hyperactivity disorder: an ALE meta-analysis. J Child Psychol Psychiatry 2006;47: 1051-1062.

11. Hopwood NJ. Pathogenesis and management of abnormal puberty. Spec Top Endocrinol Metab 1985; 7:175-236.

12. Adriani W, Leo D, Guarino M, Natoli A, Di Consiglio E, De Angelis G, et al. Short-term effects of adolescent methy/phenidate exposure on brain striatal gene expression and sexual/endocrine parameters in male rats. Ann NY Acad Sci 2006; 1074:52-73.

13. Davison BA, Kuenzel WJ. Hypothalamic biogenic amine levels in broiler chicks showing advanced sexual maturation. Poult Sci 1991;70:1610-1618.

14. Chatterjee-Chakrabarty S, Miller BT, Collins TJ, Nagamani M. Adverse effects of methy/phenidate on the reproductive axis of adolescent female rats. Fertil Steril 2005;84 Suppl 2:11311138.

15. Kelly BD, Lundon DJ, McGuinness D, Brady CM. Methy/phenidate-induced erections in a prepubertal child. J Pediatr Urol 2013;9:e1-e2.

16. Bilgiç A, Gürkan K, Türkoğlu S. Excessive masturbation and hypersexual behavior associated with methy/phenidate. I Am Acad Child Adolesc Psychiatry 2007;46:789-790.

17. Coskun M, Zoroglu S. A report of two cases of sexual side effects with OROS methylphenidate. J Child Adolesc Psychopharmacol 2009;19:477-479.

18. Levin GM, Burton-Teston K, Murphy T. Case report: development of precocious puberty in two children treated with clonidine for aggressive behavior. JChild Adolesc Psychopharmacol 1993;3:127-131. 